\section{Desde la segregación a la exclusión residencial ¿Dónde están los nuevos hogares pobres (2000- 2017) de la ciudad de Santiago, Chile?}

\section{Alejandra Rasse Figueroa \\ ORCID: https://orcid.org/0000-0003-0625-8021 \\ Centro de Desarrollo Urbano Sustentable, CEDEUS PUC, Centro de Estudios de Conflicto y Cohesión Social, COES. \\ Correo electrónico: alejandrarasse@gmail.com}

\author{
María Sarella Robles \\ ORCID: https://orcid.org/0000-0002-1803-2436 \\ Estudiante del Programa de Doctorado en Geografía de la \\ Pontificia Universidad Católica de Chile.
}

\section{Francisco Sabatini Downey \\ ORCID: https://orcid.org/0000-0001-8745-0052 \\ Doctorado en Arquitectura de la Universidad del Bío Bío, Instituto de Estudios Urbanos y Territoriales de la Pontificia Universidad Católica de Chile.}

\begin{abstract}
Resumen
La política de vivienda social subsidiada, de masiva aplicación durante los años noventa en Santiago de Chile, conformó una periferia popular altamente segregada. Desde el año 2000, la aplicación de este instrumento decrece, lo que se interpreta como un movimiento de expulsión de la vivienda social hacia el área periurbana de la ciudad. En este marco, este trabajo analiza la localización de las viviendas sociales construidas entre los años 2000 y 2017 en la Región Metropolitana de Santiago, para identificar patrones de expulsión, desplazamiento y/o segregación de los beneficiarios de esta política. A través de una estrategia mixta que combinó análisis de información secundaria, fotointerpretación de imágenes satelitales y entrevistas a los directores de obras de comunas periurbanas, concluimos que: 1) no existe evidencia de un proceso de desplazamiento masivo de hogares en vivienda social hacia el periurbano de la ciudad con posterioridad a la década de los noventa, y 2) la producción de vivienda social, tanto en la ciudad de Santiago como en su periurbano, es inferior a los nuevos requerimientos de vivienda, incrementando el déficit habitacional. Se concluye que el actual escenario es de exclusión de los nuevos hogares pobres del mercado de vivienda de Santiago, más que de desplazamiento o aumento de la segregación residencial.
\end{abstract}

\section{Palabras clave}

Desigualdades territoriales, exclusión social, pobreza urbana, política de vivienda, segregación residencial

\section{From segregation to residential exclusion Where are the new poor households (2000-2017) in the city of Santiago, Chile?}

\author{
Gonzalo Cáceres Quiero \\ ORCID: https://orcid.org/0000-0001-7498-9913 \\ Estudiante del Programa de Doctorado en Ciencias \\ Sociales, Universidad de Quilmes.
}

\section{María Paz Trebilcock \\ ORCID: https://orcid.org/0000-0001-7430-6051 \\ Escuela de Sociología de la Universidad Alberto Hurtado.}

Financiamiento: Este artículo forma parte del trabajo realizado por el proyecto Fondecyt 1171184 . Se agradece el aporte de ANID como agencia financiadora.

\begin{abstract}
The subsidized social housing policy, widely applied during the 1990s in Santiago de Chile, formed a highly segregated popular periphery. Since 2000, the application of this instrument has decreased, which is interpreted as a movement of expulsion from social housing to the peri-urban area of the city. In this framework, this work analyzes the location of social housing built between 2000 and 2017 in the Metropolitan Region of Santiago, to identify patterns of expulsion, displacement, and / or segregation of the beneficiaries of this policy. Through a mixed strategy that combined analysis of secondary information, photointerpretation of satellite images, and interviews with the director of municipal works of peri-urban distrits, we conclude that: 1) there is no evidence of a process of massive displacement of households in social housing towards the peri-urban of the city after the 1990s, and 2) the production of social housing, both in the city of Santiago and in its peri-urban, is lower than the new housing requirements, increasing the housing deficit. It is concluded that the current scenario is one of exclusion of the new poor households from the Santiago housing market, rather than of displacement or increase in residential segregation.
\end{abstract}

\section{Keywords}

Housing policy, residential segregation, social exclusion, territorial inequalities, urban poverty
HISTORIAL DEL ARTÍCULO

Recibido:

09 de enero de 2021

Aceptado:

12 de marzo de 2021 


\section{Introducción}

\section{La conformación de la periferia urbana y popular}

En la urbanización latinoamericana, la periferia casi siempre ha sido segregada y sus habitantes regularmente estigmatizados. Desde diversas disciplinas, sus ocupantes han sido llamados miserables, pobres, marginales, informales, excluidos, vulnerables y nuevamente marginales (Ahumada, 1958; Bordé, 1954; Comisión Económica para América Latina y el Caribe [CEPAL], 1963; Gorelik, 2008; Hauser, 1967). Sin perjuicio del momento en que ha ocurrido el análisis, los contornos expansivos de las metrópolis latinoamericanas suelen ser identificados con el hacinamiento poblacional, la obsolescencia habitacional, la degradación ambiental y la presencia de altos grados de homogeneidad social (Aguilar, Ward \& Smith Sr, 2003; Calderón, 2003; Elorza, 2016; Hidalgo, 2007; Pírez, 1994; Queiroz, 2003; Sabatini, Cáceres y Cerda, 2001). La periferia, de este modo, queda descrita como un conglomerado en que coinciden estos individuos y problemáticas.

Las políticas de vivienda y acceso al suelo explican parte importante de las periferias que se han ido sedimentando en las ciudades latinoamericanas. Santiago de Chile no es diferente. Si bien durante el ciclo reformista (en la década de los sesenta e inicios de los setenta) el Estado ensayó proyectos habitacionales de integración socioespacial (Cáceres, 2017), impulsando conjuntos crecientemente cualificados y bien localizados a través de subsidios a la oferta, a cinco años de instaurada, la dictadura militar de Augusto Pinochet desmanteló dicho arreglo. En su lugar, estableció un modelo de provisión de vivienda social y acceso al suelo basado en el subsidio a la demanda, que se masificó y consolidó durante los años noventa (bajo gobiernos elegidos). Este modelo urbano-habitacional para hogares de bajos ingresos - que por sus características ha sido referido como liberalismo autoritario, neoliberalismo urbano o neoliberalismo subsidiario- ha tenido un reconocido efecto segregador (Hidalgo, 2007; Sabatini, 2000; Sabatini et al., 2001), y a lo largo del tiempo se cristalizó en una periferia homogénea en términos de pobreza y tipologías de vivienda, precaria en materia de servicios y equipamiento, tanto en Santiago (Ducci, 1997; Rodríguez y Sugranyes, 2004), como en todas las ciudades metropolitanas chilenas, e incluso en algunas ciudades intermedias (Sabatini, Wormald y Rasse, 2013).

En términos de diseño, el efecto segregador de los instrumentos de provisión de vivienda social está intrínsecamente vinculado con su forma de operación. En su versión original, el "subsidio habitacional" contaba con tres componentes: 1 ) un pequeño monto de ahorro previo por parte de las familias (aun así, difícil de conseguir por las condiciones de precariedad económica de estos hogares); 2) un subsidio provisto por el Estado para aquellos que lograran reunir el ahorro (que en la práctica cubría la mayor parte del costo de la vivienda); y 3) un crédito hipotecario obtenido por cada familia en el mercado privado, que permitía cubrir la diferencia entre el valor de la vivienda, y lo reunido entre subsidio y ahorro. Una vez obtenido el subsidio, cada familia debía buscar una vivienda en el mercado habitacional privado entre una serie de conjuntos habitacionales que cumplían con los requisitos para la aplicación del beneficio (relativos a características materiales y precio máximo), y conseguir un crédito hipotecario que les permitiera completar el precio de su vivienda.

En la práctica, la oferta de vivienda social se localizó en sectores alejados, aun agrícolas, donde no solo el suelo era más barato, sino que además le daba al agente inmobiliario la oportunidad de obtener ganancias por la conversión de suelo rural en urbano, con la consecuente capitalización de las rentas del suelo (Sabatini, 2000). Complementariamente, se trató, muchas veces, de unidades habitacionales muy pequeñas, en entornos aún sin completar su urbanización y conexión (vial, de transporte público) con la ciudad, y subprovistas de equipamientos. De esta forma, la oferta de vivienda al alcance de los hogares pobres favorecidos con el subsidio habitacional intensificó su localización periférica y segregada (Castillo e Hidalgo, 2007; Imilan, Olivera y Beswick, 2016; Sabatini et al., 2001). 
Al observar las consecuencias de la aplicación de este instrumento en términos cronológicos, durante la década de los ochenta, la construcción de vivienda social en zonas periféricas previamente rurales se vio complementada con la erradicación de los campamentos ${ }^{1}$ localizados en el centro y en el oriente de la ciudad de Santiago, donde residen mayoritariamente los hogares de mayores ingresos, hacia los conjuntos de vivienda social de reciente construcción, ubicados principalmente en la periferia sur de la capital (Molina, 1985; Morales y Rojas, 1986). Este desplazamiento reforzó el patrón de segregación residencial socioeconómica en formación.

Luego, durante los años noventa se generó la mayor producción de vivienda social de la historia del país (Imilan Ojeda, 2016). El fuerte déficit habitacional que tuvieron que enfrentar los primeros gobiernos civiles impulsó la masificación de la asignación de subsidios habitacionales, como una vía para descomprimir la demanda por vivienda desde los grupos de menores ingresos. Se generó masiva demanda por vivienda social, en el marco de regulaciones urbanas sumamente laxas. La desruralización promovida por el Estado aceleró las oportunidades expansión. Se produjo, entonces, una fuerte oferta de vivienda social hacia los bordes, colaborando con la consolidación de una periferia segregada de bajos ingresos.

En suma, durante las dos primeras décadas de aplicación de la política de voucher (1980-2000), se habían construido 203.236 viviendas sociales en la ciudad de Santiago (Tapia, 2011), reduciendo drásticamente las estadísticas de déficit habitacional, y conformando un gran arco geográfico de vivienda social, que demarcaba los bordes norte, sur y oeste de la ciudad. Alcanzaba así su máxima expresión el patrón de segregación socioespacial del Gran Santiago, con esa periferia homogénea de bajos ingresos, un centro de ingresos medios y altos que se había proyectado hacia el este, y sectores pericentrales mixtos de estratos medios.

\section{Cambios en las condiciones de acceso al suelo: la expulsión de la vivienda social nueva}

Las condiciones de producción de la periferia popular y acceso a la vivienda por parte de los hogares de menores ingresos - recién descritas - cambiaron de forma importante hacia principios de la primera década del año 2000. Luego de casi veinte años de producción masiva de vivienda social en la periferia de la ciudad de Santiago, se observó la proliferación de conjuntos de vivienda destinados a segmentos medios y medio altos en dichas localizaciones (Hidalgo, 2004; Janoschka, 2002; Sabatini, 2000).

La constitución de un sector inmobiliario capaz de desarrollar proyectos residenciales atractivos más allá de las características de su entorno ha sido factor central de dicha transformación. La mayor capacidad de pago por el suelo de los nuevos condominios de estratos medios -en comparación con los proyectos de vivienda socialexplica alzas considerables de los precios del suelo, las que han pasado a constituir una barrera estructural para la construcción de vivienda social por empresas privadas (Sabatini, Campos, Cáceres y Blonda, 2007). En efecto, a partir del año 2000 se observa un descenso marcado y creciente en la producción de vivienda social en el Área Metropolitana del Gran Santiago (AMGS) (Hidalgo, 2007; Tapia, 2014). Emerge, así, una diferencia entre los hogares pobres que consiguieron una vivienda social en la periferia segregada del AMGS, y los nuevos hogares pobres, que ya no parecen poder acceder a una vivienda en sus comunas de origen (Sabatini et al., 2007).

En ese contexto, diversos investigadores, basados en los datos agregados de producción de vivienda social emanados desde el Ministerio de Vivienda de Urbanismo (MINVU), concluyeron que se estaría produciendo un proceso expulsivo de la vivienda social, ya no hacia la periferia, sino hacia sectores del periurbano metropolitano - esta conclusión aparece explícita en trabajos como

1 Palabra utilizada en Chile para referir a los slums o asentamientos informales precarios y que vino a reemplazar, desde la década del sesenta, a la expresión poblaciones callampas. 
los de Hidalgo (2007) y Tapia (2014), pero corresponde, en la práctica, a un diagnóstico mucho más extendido que también compartimos los autores de este texto-.

¿Dónde se ha estado localizando a partir de la primera década del año 2000 la vivienda social para hogares populares del Gran Santiago, que antes, especialmente durante los años ochenta y noventa, se construía en la periferia segregada del AMGS? Estas localizaciones, ¿refuerzan o desafían el patrón de localización de vivienda social que se había consolidado en las dos décadas previas? Responder ambas preguntas obliga a analizar la localización de las viviendas sociales construidas entre los años 2000 y 2017, identificando patrones de expulsión, desplazamiento, y/o segregación de los hogares del AMGS beneficiarios de esta política. Para dar cuenta de este objetivo, revisaremos, haciendo foco en la realidad de las ciudades latinoamericanas, algunas de las articulaciones posibles entre marginalidad, segregación, desplazamiento y exclusión social. Luego, se expondrá de forma detallada la metodología utilizada. En tercer lugar, se discuten los resultados obtenidos. Finalmente, se presentan las principales conclusiones del estudio y las hipótesis que se abren hacia indagaciones futuras.

\section{Marco conceptual: enlazando exclusión, segregación y desplazamiento en el análisis del acceso al suelo y la vivienda}

En los estudios que abordan las zonas de localización de los hogares más desaventajados en las metrópolis latinoamericanas, confluyen diversos conceptos que permiten describir la realidad de sus habitantes, entre los más habituales, pobreza, marginalidad, exclusión y segregación. En la experiencia chilena, los primeros estudios sobre políticas habitacionales, desarrollo urbano y crecimiento en extensión incluyen una crítica constante al sesgo segregador del Estado. Para los arquitectos-urbanistas modernos, en décadas tan tempranas como las del cuarenta y cincuenta, la habitación popular reclamaba buenas localizaciones y viviendas dotadas de confort material (Cariola y Soler, 1969; Parraguez, 1947).

\section{Marginalidad urbana}

Desde fines de los años cincuenta en la Comisión Económica para América Latina y el Caribe (CEPAL), pero también desde el Centro para el Desarrollo Económico y Social de América Latina (DESAL), fueron conducidos diversos análisis con foco específico en las periferias populares latinoamericanas. Con sede en Santiago, ambas instituciones utilizaron la marginalidad urbana como clave interpretativa, forjando una teoría comprensiva que suscitó una de las primeras controversias interdisciplinarias por las que atravesaron las ciencias sociales en América Latina (Sabatini, 1977). Para los investigadores del DESAL, la persistencia de la pobreza estaba dada por una suma de factores culturales, históricamente construidos desde la época de la conquista (DESAL, 1967), siendo la interacción de estas pautas culturales con cuestiones estructurales las que obstaculizaban la participación de estos hogares de los bienes y recursos, y su constitución como sujetos sociales (DESAL, 1964). En este sentido, esta propuesta se distancia de la noción de cultura de la pobreza desarrollada por Lewis (1972), en tanto reconoce limitantes estructurales en los procesos de incorporación de los pobres al bienestar.

Frente a la pasividad relativa que se suele atribuir a la imaginativa obra de Lewis y al sesgo filocompasivo que anega los textos de Vekemans, diversos trabajos subrayaron la capacidad de los sectores populares para convertirse en sujetos activos en la demanda de suelo, bienes y poder, activando todo tipo de estrategias, pero desde una condición desaventajada (Giusti, 1973; Perlman, 1976; Roberts, 2007).

\section{Exclusión}

En los años noventa, el concepto de exclusión vino a substituir en importancia al de marginalidad o informalidad en el análisis de la pobreza urbana. Exclusión e incluso apartheid acentúan la relación que los sujetos establecen con el conjunto de la sociedad y sus estructuras. En este sentido, si bien es posible afirmar una continuidad con la noción de marginalidad recién revisada, implica abandonar el foco en "los pobres", para poner atención en las relaciones que permiten 
que los sujetos queden incluidos o excluidos de una determinada esfera social (Roberts, 2007). Esto trae consigo varias implicancias, de las cuales consideramos dos como centrales para este trabajo. En primer lugar, que las inclusiones, especialmente en América Latina, son parciales, es decir, un sujeto puede estar incluido en una esfera y excluido en otra, ya que ninguna esfera tiene la fuerza como para sostener a las demás, como es el caso del empleo formal protegido en un Estado de Bienestar (Kaztman y Wormald, 2002). En segundo lugar, que, pese a que las exclusiones se dan por esfera, en la práctica muchas de ellas están encadenadas, es decir, experimentar una exclusión hace más probable estar excluido también en otras dimensiones de la vida social. Saraví (2007) se refiere a esto desde dos conceptos: biografías de exclusión y acumulación de desventajas. Las desventajas se acumulan en ciertos sujetos, que entonces desarrollan biografías de exclusión. De acuerdo con mismo autor (Saraví, 2020), estos procesos adquieren especial notoriedad en el territorio. Se llega a residir en una zona de pobreza urbana producto de una cadena de exclusiones previas y, a su vez, el residir en ese lugar desencadena una serie de nuevas desventajas y exclusiones.

\section{Segregación}

Es en este punto donde el concepto de exclusión engrana con la noción de segregación, entendida como el grado en que dos o más grupos se encuentran separados en el espacio urbano (Massey \& Denton, 1988). La segregación de los hogares más pobres cuenta la exclusión como parte de sus factores causales, y también se asocia a la generación de nuevas exclusiones.

Si ponemos el foco en sus factores causales, la segregación residencial socioeconómica está íntimamente vinculada con el funcionamiento de los mercados de suelo, en especial en ciudades en que la regulación urbana es baja y el mercado se transforma en el principal mecanismo de asignación de suelo (Harvey, 1973). Algunos autores señalan que la centralidad del mercado de suelo y sus consecuencias son solo un síntoma visible de la estructura y del modelo económico, que son los que en la práctica dan forma a la ciudad. Entre ellos, algunos apuntan a la segregación residencial como una forma de exclusión de ciertos grupos sociales (ver, por ejemplo, Wacquant, Slater \& Pereira, 2014) y, en ese sentido, relevan que detrás de los mecanismos normativos o de ciertas políticas territoriales (habitacionales, de seguridad, etc.) hay en la práctica un ejercicio de poder del Estado que tiene por función sustentar jerarquías sociales y espacios de privilegio y/o descrédito.

En términos de sus consecuencias, la segregación residencial de los hogares más pobres ha sido asociada a exclusiones y dificultades en el acceso a las diversas oportunidades de la ciudad, al surgimiento de estigmas territoriales y, en suma, a un aumento de la desigualdad (Rasse, 2019).

En este marco de análisis, la política de vivienda basada en voucher promovió, durante los años ochenta y noventa, la inclusión de los hogares populares en el mercado habitacional formal, generando, de esta forma, acceso al suelo urbano. Uno podría pensar que la inclusión en la vivienda formal generaría un círculo virtuoso, promoviendo la inclusión en otros ámbitos (De Soto, 1987). Muy por el contrario, esta fórmula de acceso a la vivienda fue de la mano de una localización periférica y segregada, lo que implica que estos hogares enfrentaron una serie de desventajas y nuevas exclusiones. Desde la perspectiva de los hogares de bajos ingresos, lo anterior se presentaba como la disyuntiva entre acceder a una vivienda en propiedad en esos sectores u optar a una mejor localización a través de otro tipo de solución habitacional informal, como vivir en un campamento, hacinados o allegados ${ }^{2}$ o arrendar cuartos o espacios subestándar, como se sugiere en Brain, Prieto y Sabatini (2010).

2 En Chile, se denomina allegamiento a aquella situación habitacional en que dos hogares, con presupuestos y prácticas cotidianas separadas, conviven en una misma vivienda, sin mediar arrendamiento, sino que como forma de enfrentar la carencia de vivienda de uno de los dos hogares, propiciado por la existencia de vínculos de parentesco o amistad entre ambos. 


\section{Desplazamiento}

Desde fines de los años ochenta o incluso antes, la periferia popular segregada es intervenida por proyectos inmobiliarios orientados a grupos de ingresos medios y altos. La aproximación física no ocurre solo en Santiago de Chile, sino que está documentada para diversas metrópolis latinoamericanas (ver, por ejemplo, Janoschka \& Borsdorf, 2004; Portes, 1989). Tan temprana como la proximidad, es la refutación a que se estén generando lazos comunitarios que puedan ser entendidos más allá de lo puramente funcional.

El acercamiento reduce las distancias físicas entre grupos de distinto estrato socioeconómico, pero también genera mayor presión por el suelo, elevando su valor, y dificultando el acceso de los más pobres (por la vía formal). Dos líneas teóricas parecen productivas para analizar este fenómeno: 1) la renta del suelo y 2) la que se ocupa de la dimensión territorial de las desigualdades sociales.

En cuanto a lo primero, el análisis de la producción y capitalización de "brechas de renta" (Smith, 1987) permite entender la proliferación de condominios para grupos medios y altos en áreas pobres segregadas y su consecuencia en la elevación de los precios del suelo. La exclusión de los proyectos de vivienda social de esas áreas sería el resultado del funcionamiento de los mercados de suelo en el marco de estos procesos de gentrificación de la periferia popular, en el marco de lo que Slater (2009) llama presión de desplazamiento.

La presión de desplazamiento por gentrificación ha sido ampliamente debatida y documentada para el caso del centro y pericentro de la ciudad de Santiago (ver, por ejemplo, López Morales, 2013, o Inzulza y Galleguillos, 2014). Sin embargo, las transformaciones experimentadas en periferias populares latinoamericanas han sido trabajadas a través de los conceptos de fragmentación y polarización (ver, por ejemplo, Hidalgo y Borsdorf, 2005; Hidalgo, Borsdorf, Zunino y Álvarez, 2008, Janoschka, 2002; Link, 2008;), más que desde la idea de desplazamiento. En cuanto a la dimensión territorial de las desigualdades sociales, la construcción de los proyectos gentrificadores implica una reducción de la segregación socioespacial, en términos de distancia física entre los grupos sociales (Hidalgo, 2004, 2007; Sabatini y Cáceres 2004; Sabatini y Salcedo, 2007). Los nuevos condominios quedan próximos, incuso colindantes con la vivienda social antigua. Incluso una parte de los compradores de las viviendas en esos condominios son nuevos hogares que tienen su origen en barrios populares, pero han experimentado procesos de movilidad social ascendente (Rasse, 2015; Robles, 2009; Sabatini, Rasse, Cáceres, Robles y Trebilcock, 2017), lo que establece continuidades entre ambos grupos.

Sin embargo, la construcción social de la desigualdad va más allá de la segregación y de la proximidad o la distancia física. La producción de estos nuevos espacios se asocia a la construcción de nuevas identidades sociales, que Savage (2010) intenta capturar con la noción de espacialización de la clase social. Esto ha sido documentado para los grupos de altos ingresos en Santiago, tanto en términos de construcción identitaria desde el barrio por Salcedo y Rasse (2017), como en relación con los proyectos identitarios de movilidad social por Méndez y Gallo (2018). En consecuencia, más allá la restricción que proviene del valor de suelo, también debe comprenderse que el suelo vacante y las posibilidades de desarrollo futuro de estos sectores están pensadas (desde los nuevos vecinos, los propietarios del suelo y los desarrolladores inmobiliarios) en términos de la construcción de nuevas identidades territoriales. Con esto, a la restricción proveniente del valor del suelo se suma muchas veces la resistencia de los vecinos de mayores ingresos a la construcción de conjuntos de vivienda social (Galleguillos, 2000).

Desde el punto de vista de los hogares de menores ingresos, la baja en la producción de vivienda social en la periferia consolidada implicaría una agudización de la tensión entre propiedad formal y localización descrita más arriba: si antes la disyuntiva se constituía entre acceder a una vivienda formal en la periferia segregada o resolver la necesidad de vivienda a través de allegamiento o vivienda informal (campamento) en una mejor localización, es posible hipotetizar que 
en la actualidad los hogares se verían enfrentados a decidir entre una vivienda formal fuera de la ciudad, en el periurbano, o mantenerse dentro de la ciudad en condiciones de informalidad o de habitabilidad más precaria. De ser así, el mencionado trade off estaría operando en una escala mayor, de alcance regional, en lo que podríamos denominar región urbana de Santiago.

\section{Metodología}

Se utilizó una estrategia mixta, que combinó análisis estadístico de datos secundarios que provienen del Censo de Población y Vivienda 2012, la Encuesta de Caracterización Socioeconómica Nacional, CASEN 2017, y del Catastro de Condominios Sociales del Ministerio de Vivienda y Urbanismo (2021) y análisis de datos primarios que complementan estos hallazgos, específicamente, un set de entrevistas a directores de obras, asesores urbanos y secretarios comunales de planificación, SECPLA, de 14 de las 18 comunas del periurbano de la Región Metropolitana, más una encuesta a 700 hogares residentes en 12 conjuntos habitacionales en comunas periurbanas en zonas de expansión del AMGS.

En lugar de utilizar datos agregados de producción de vivienda a nivel de comuna, como los estudios previos sobre el tema, se optó por combinar los datos georreferenciados de producción de vivienda social, con el análisis de bases de datos censales que permitieran (utilizando variables de comuna de nacimiento, migración y movilidad) aproximarse a la noción de desplazamiento (desde el AMGS a comunas periurbanas), y dar cuenta de las características socioeconómicas de los hogares emplazados en las áreas hacia las cuales estarían siendo expulsados los hogares de bajos ingresos. Lo anterior nos permitió tener un panorama integral respecto de los atributos de la localización de los hogares que residen en vivienda social en la ciudad de Santiago (incorporando sus zonas de expansión), y del rol que la política de vivienda está jugando en la segregación de la ciudad en la actualidad. El trabajo se organizó en varias etapas.

\section{Primera etapa: identificación de las áreas de expansión del Gran Santiago}

Un primer paso fue identificar las áreas que se considerarían como expansión del AMGS, para tener un marco espacial que permitiera enfocar el análisis. Si bien la consideración del Gran Santiago como un conjunto de 34 comunas es extendida en trabajos académicos y en políticas públicas, no existe consenso en torno a qué territorios considerar o anexar para dar cuenta de su expansión en la última década. Por esto se consideró una etapa previa de análisis que permitiera configurar el marco espacial del Gran Santiago más sus áreas de expansión. Para esto, se trabajó con los censos 2002 y $2012^{3}$, identificando aquellas zonas que tuvieran 1) una proporción de migrantes recientes similar a la detectada en la periferia consolidada en la década anterior (indicador de estar en proceso de urbanización o captura de nuevos residentes); 2) una proporción de nacidos en comunas del AMGS mayor al promedio de nacidos en comunas del AMGS (distinta de la actual residencia) en la periferia consolidada en la década anterior (como indicador de arraigo a la ciudad); y 3) una proporción de personas que trabajan o estudian en el AMGS mayor al 50\% (como indicador de dependencia funcional). La definición de estos tres criterios se realizó a partir de una serie de 10 entrevistas semiestructuradas a investigadores nacionales con publicaciones recientes en temas de expansión urbana, periurbanización y áreas urbanas funcionales, y la consulta de las principales publicaciones acerca de la expansión urbana de Santiago de Chile de los últimos 10 años. Referentes clave en este proceso fueron: Ortiz y Morales (2002); Hidalgo, Salazar, Lazcano, Roa, Álvarez y Calderón (2005); Ducci (2002), Salazar y Osses (2008), Fuentes y Pezoa (2018).

3 Se decidió utilizar el Censo 2012, pese a los cuestionamientos existentes, ya que para el área de estudio presenta niveles razonables de completitud: el promedio de omisión en las comunas de la Región Metropolitana alcanza un 8\%. Adicionalmente, se realizó un trabajo previo de preparación de la base de datos, subsanando inconsistencias y eliminando los casos imputados (se trabajó solo con las viviendas efectivamente censadas). 
Tabla 1

Variables y criterios de fotointerpretación

\begin{tabular}{lll} 
Variable & Atributos & Descripción \\
\hline Tipología de ocupación & $\begin{array}{l}\text { Parcela, villa, condominio, parcela } \\
\text { de agrado, sitio, caserío }\end{array}$ & $\begin{array}{l}\text { Se elaboró, de modo previo a la fotointerpretación, una lista de las tipologías } \\
\text { existentes en las áreas de expansión a partir de estudios previos (Hidalgo, } \\
\text { 2004, 2007; Hidalgo et al., 2005). Se dejó abierta la posibilidad de identificar } \\
\text { otras tipologías. }\end{array}$ \\
\hline Tamaño & Metros cuadrados & $\begin{array}{l}\text { Se midió tamaño de cada polígono homogéneo identificado, utilizando la } \\
\text { herramienta de medición disponible en Google Earth. }\end{array}$ \\
\hline Uso & Residencial, agrícola, mixto & $\begin{array}{l}\text { Se determinó a partir de la observación del uso predominante de cada lote. } \\
\text { Nivel socioeconómico }\end{array}$ \\
\hline & Alto, medio-alto, medio, bajo & $\begin{array}{l}\text { Se caracterizó cualitativamente el nivel socioeconómico a través de la } \\
\text { observación de las características de materialidad, estado y tamaño de la } \\
\text { vivienda, las características del lote (tamaño, tenencia de piscinas, jardines), } \\
\text { y las características del conjunto y el entorno (infraestructura deportiva, } \\
\text { áreas verdes, características de los cerramientos), utilizando para esto tanto } \\
\text { la imagen satelital como la herramienta Street View. }\end{array}$ \\
\hline
\end{tabular}

Las zonas identificadas se representaron en planos, y luego se realizó un trabajo de fotointerpretación de todas las zonas identificadas, así como de la totalidad de las zonas urbanas de las comunas en que estaban emplazadas. Se clasificó lo analizado en términos de tipología de la vivienda y nivel socioeconómico observado, según las características de la vivienda, el conjunto habitacional y el sitio (Tabla 1).

Con posterioridad a la fotointerpretación, se realizó una validación de esta clasificación a través de su correlación con indicadores censales indirectos (densidad habitacional e índice sociomaterial territorial ${ }^{4}$, calculados con base al Censo 2017), para identificar y resolver inconsistencias.

\section{Segunda etapa: localización de los conjuntos de vivienda social posterior al año 2000 en el Gran Santiago y sus áreas de expansión}

Para identificar las zonas de emplazamiento de los conjuntos de vivienda social, se trabajó con la base georreferenciada de conjuntos de vivienda desarrollada por Ministerio de Vivienda y Urbanismo, identificando aquellos conjuntos correspondientes a vivienda orientada a los segmentos de menores ingresos ${ }^{5}$ (es decir, eliminando los programas orientados a estratos medios y medios bajos), y realizando cortes temporales que permitieran comparar las tendencias de localización de las viviendas sociales en distintos períodos de tiempo. Los cortes temporales se realizaron de acuerdo con las etapas mencionadas por los diversos autores arriba revisados (antes de 1980, 1980-2000, 2001-2017), incorporando conjuntos hasta 2017, que es el último año que registra la base del ministerio.

\section{Tercera etapa: identificación de procesos de} desplazamiento desdeelAMGS a laszonas de expansión

Para identificar si los conjuntos emplazados en las comunas periurbanas a partir del año 2000 correspondían a desplazamientos de habitantes del AMGS o a soluciones habitacionales para demanda de esas mismas comunas, se realizaron entrevistas a los directores de obras municipales y/o asesores urbanos de 14 de las 18 las comunas periurbanas de la Región Metropolitana (no se realizaron entrevistas en María Pinto, Alhué, El Monte y San Pedro, ya que de acuerdo con el análisis censal no presentaban indicios de dependencia funcional, o fuertes procesos migratorios respecto del AMGS en

4 Desarrollado por el Observatorio de Ciudades UC con base en características de la vivienda y nivel educativo. Su detalle puede revisarse en observatoriodeciudades.com

5 Los programas de vivienda orientados al segmento más pobre de la población han cambiado continuamente de nombre y se han dado bajo diversas modalidades. Se consideró como vivienda social aquella que correspondiera, en cada momento, al programa habitacional orientado a cubrir la demanda de los hogares más pobres (programas de Vivienda Básica, Vivienda Social Dinámica sin Deuda, Fondo Solidario de Vivienda I, entre otros). 
los últimos años). En estas entrevistas se contrastó lo observado en el análisis censal y de fotointerpretación, pero centralmente, se consultó acerca de los conjuntos de vivienda social que existen en la comuna, y el origen territorial de sus habitantes: si provenían de la misma comuna, o tenían su origen en el AMGS. También se consultó si en la actualidad se estaba desarrollando vivienda social y en qué sectores de la comuna estaba ocurriendo esto.

Adicionalmente, este trabajo se benefició de una encuesta a 700 jefes de hogar y/o cónyuges en 12 conjuntos de vivienda social localizados a partir del año 2000 en comunas del periurbano de la Región Metropolitana de Santiago, en las que, entre otras cosas, se consultó por su historia residencial, para saber de qué comunas provenían antes de llegar su actual vivienda.

\section{Cuarta etapa: análisis de datos disponibles en torno al déficit habitacional en el AMGS}

Por último, para complementar la visión respecto de la localización de la vivienda social nueva, y disponer de material complementario que permitiera la interpretación, se revisaron los datos secundarios disponibles en el observatorio habitacional del MINVU, para realizar un análisis de la tendencia de los distintos componentes del déficit habitacional ${ }^{6}$ en el AMGS, desde los años noventa a la actualidad, con base en datos de la encuesta CASEN. Asimismo, se desarrolló un análisis del Censo 2017, para localizar los sectores con mayor déficit al interior del AMGS.

\section{Resultados empíricos}

\section{La producción de vivienda social en el AMGS y sus zonas de expansión}

Al triangular los datos provenientes de las bases del MINVU la fotointerpretación de las zonas de expansión de la ciudad, y las entrevistas con los directores de obras municipales, se puede concluir que no existe en los últimos 20 años (es decir, a partir del año 2000) un proceso masivo de migración de hogares de bajos ingresos desde el AMGS hacia las zonas de expansión sobre el periurbano.

Por una parte, la producción de vivienda social a partir del año 2000 es mucho menor a la de las dos décadas anteriores (Figura 1; Tabla 2). En este sentido, si bien la proporción de vivienda en comunas del periurbano en el período 2001-2017 es mucho mayor a la del período anterior (1980-2000), el incremento en el número absoluto de unidades no es significativo: el aumento de unidades en el periurbano corresponde a menos de un 5\% de la disminución de las unidades de vivienda en la periferia. Este segundo dato descarta un desplazamiento de la oferta de vivienda desde el AMGS hacia comunas del periurbano.

\section{Origen de los asignatarios de vivienda social posterior al año 2000 en zonas de expansión del AMGS}

Los datos censales, los provenientes de las entrevistas a los directores de obras y asesores urbanos, además de aquellos correspondientes a las encuestas a hogares son consistentes en sugerir que la oferta de vivienda social en las comunas del periurbano está destinada mayoritariamente a solucionar su déficit habitacional interno.

En términos de datos censales, no se reportan en el Censo 2017 niveles de migración reciente desde el AMGS en las zonas censales correspondientes a las zonas en que se localizan los conjuntos de vivienda social construidos en el período (ver Tabla 3).

Asimismo, los entrevistados fueron enfáticos en señalar que los conjuntos de vivienda construidos a partir de 2000 correspondían a proyectos desarrollados para paliar su propio déficit habitacional comunal (salvo dos excepciones

6 El déficit habitacional fue calculado con base en la metodología propuesta por el Minvu, siguiendo los lineamientos de CELADE. Esta puede ser revisada en el documento El déficit habitacional en Chile (MINVU (2004). 
Figura 1

Vivienda social en el AMGS, según período de edificación

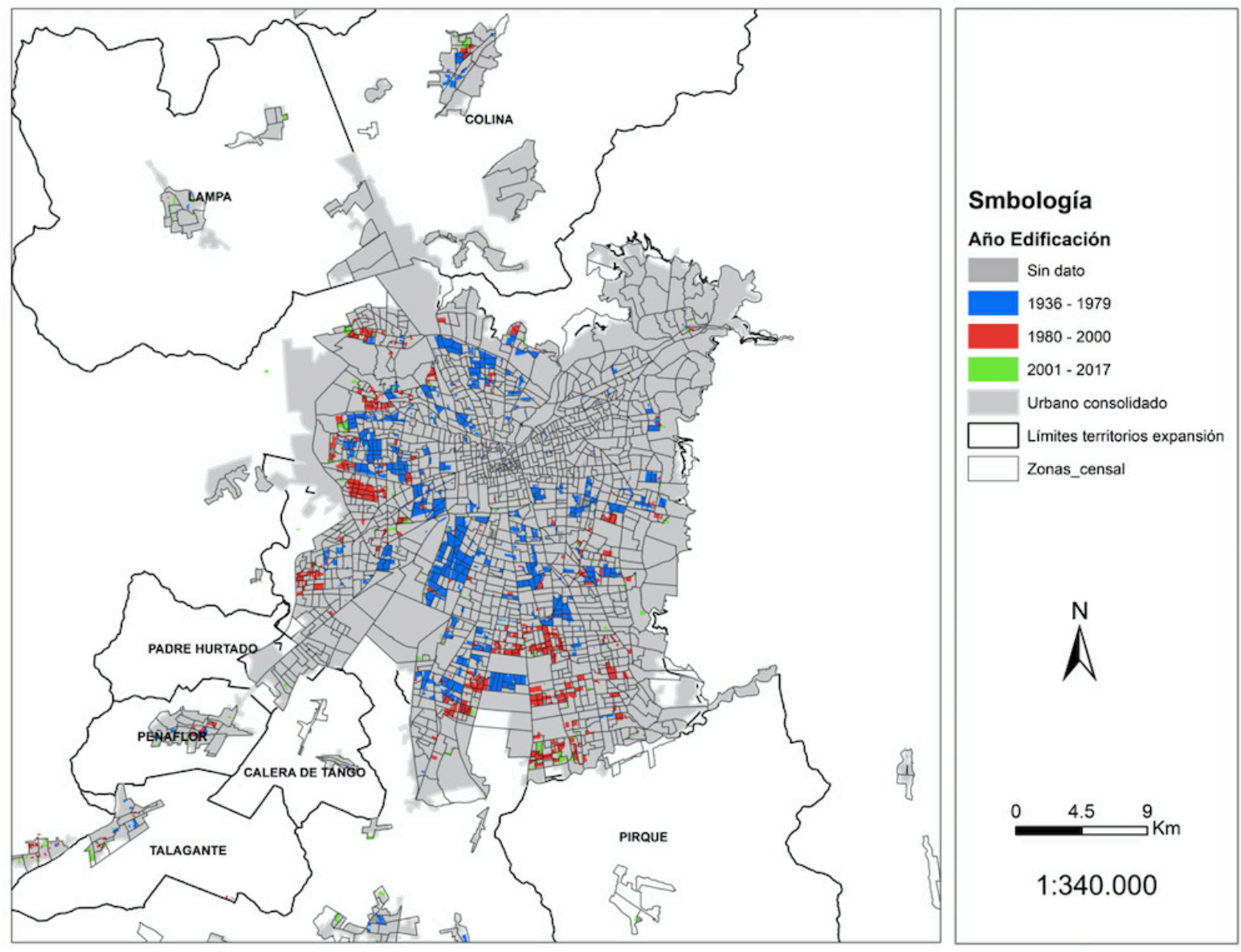

Tabla 2

Vivienda social en la Región Metropolitana de Santiago, según período de edificación y tipo de comuna

\begin{tabular}{|c|c|c|c|c|c|c|}
\hline & \multicolumn{2}{|c|}{ 1939-1979 } & \multicolumn{2}{|c|}{$1980-2000$} & \multicolumn{2}{|c|}{ 2001-2017 } \\
\hline Localización & $\mathbf{N}^{\circ}$ & $\%$ & $\mathbf{N}^{\circ}$ & $\%$ & $\mathbf{N}^{\circ}$ & $\%$ \\
\hline Cono alta renta & 20.274 & $10 \%$ & 3.302 & $1 \%$ & 1.298 & $2 \%$ \\
\hline Centro-pericentro & 109.306 & $52 \%$ & 34.933 & $15 \%$ & 10.682 & $16 \%$ \\
\hline Periferia & 68.927 & $33 \%$ & 175.888 & $77 \%$ & 33.478 & $51 \%$ \\
\hline Periurbano & 11.143 & $5 \%$ & 13.288 & $6 \%$ & 19.652 & $30 \%$ \\
\hline Total & 209.650 & $100 \%$ & 227.411 & $100 \%$ & 65.110 & $100 \%$ \\
\hline
\end{tabular}

Nota: En esta tabla se han incluido todas las viviendas correspondientes a conjuntos de los cuales se pudo determinar su año de construcción. Quedaron excluidas 7.438 viviendas de las cuales no se pudo obtener este dato (correspondientes a un 2,6\% del total de viviendas catastradas).

Fuente: Elaboración propia con base en el catastro de condominios sociales, MINVU, 2017. 
Tabla 3

Porcentaje de migración reciente en zonas receptoras de viviendas sociales en comunas periurbanas de la Región Metropolitana, en comparación con zonas sin viviendas sociales, Censo 2017

\begin{tabular}{|c|c|c|c|c|c|c|c|c|c|c|c|c|}
\hline \multirow[b]{2}{*}{ Comuna } & \multicolumn{6}{|c|}{ Zona con viviendas sociales } & \multicolumn{6}{|c|}{ Zonas sin viviendas sociales } \\
\hline & $\begin{array}{c}\text { No } \\
\text { migrantes }\end{array}$ & $\%$ & $\begin{array}{l}\text { Migrantes } \\
\text { AMGS }\end{array}$ & $\%$ & $\begin{array}{c}\text { Otra } \\
\text { comuna o } \\
\text { país }\end{array}$ & $\%$ & $\begin{array}{c}\text { No } \\
\text { migrantes }\end{array}$ & $\%$ & $\begin{array}{l}\text { Migrantes } \\
\text { AMGS }\end{array}$ & $\%$ & $\begin{array}{c}\text { Otra } \\
\text { comuna o } \\
\text { país }\end{array}$ & $\%$ \\
\hline Colina & 5.067 & $78,8 \%$ & 985 & $15,3 \%$ & 378 & $5,9 \%$ & 17.972 & $71,0 \%$ & 5.024 & $19,8 \%$ & 2.325 & $9,2 \%$ \\
\hline Lampa & 4.657 & $79,0 \%$ & 868 & $14,7 \%$ & 370 & $6,3 \%$ & 10.861 & $63,0 \%$ & 5.199 & $30,2 \%$ & 1.168 & $6,8 \%$ \\
\hline Til Til & 205 & $79,8 \%$ & 11 & $4,3 \%$ & 41 & $16,0 \%$ & 2.125 & $74,7 \%$ & 461 & $16,2 \%$ & 258 & $9,1 \%$ \\
\hline Buin & 2.913 & $89,3 \%$ & 233 & $7,1 \%$ & 117 & $3,6 \%$ & 15.808 & $75,6 \%$ & 3.497 & $16,7 \%$ & 1.615 & $7,7 \%$ \\
\hline Paine & 3.856 & $86,0 \%$ & 274 & $6,1 \%$ & 356 & $7,9 \%$ & 5.548 & $83,5 \%$ & 612 & $9,2 \%$ & 481 & $7,2 \%$ \\
\hline Melipilla & 5.996 & $85,1 \%$ & 493 & $7,0 \%$ & 559 & $7,9 \%$ & 16.871 & $87,8 \%$ & 943 & $4,9 \%$ & 1.407 & $7,3 \%$ \\
\hline Curacaví & 3.316 & $90,3 \%$ & 186 & $5,1 \%$ & 170 & $4,6 \%$ & 2.125 & $90,8 \%$ & 119 & $5,1 \%$ & 97 & $4,1 \%$ \\
\hline Talagante & 3.216 & $92,3 \%$ & 94 & $2,7 \%$ & 173 & $5,0 \%$ & 11.610 & $85,8 \%$ & 907 & $6,7 \%$ & 1.018 & $7,5 \%$ \\
\hline El Monte & 4.423 & $82,5 \%$ & 393 & $7,3 \%$ & 544 & $10,1 \%$ & 3.137 & $88,1 \%$ & 181 & $5,1 \%$ & 243 & $6,8 \%$ \\
\hline Isla de Maipo & 2.477 & $86,8 \%$ & 210 & $7,4 \%$ & 166 & $5,8 \%$ & 4.471 & $88,5 \%$ & 257 & $5,1 \%$ & 326 & $6,5 \%$ \\
\hline Padre Hurtado & 1.543 & $79,5 \%$ & 305 & $15,7 \%$ & 93 & $4,8 \%$ & 10.165 & $71,8 \%$ & 3.161 & $22,3 \%$ & 840 & $5,9 \%$ \\
\hline Peñaflor & 3.133 & $78,9 \%$ & 597 & $15,0 \%$ & 241 & $6,1 \%$ & 16.917 & $84,8 \%$ & 2.029 & $10,1 \%$ & 1.102 & $5,5 \%$ \\
\hline
\end{tabular}

Nota. Elaboración propia con base en datos censales.

puntuales en la zona poniente, correspondientes a vivienda económica, no $\operatorname{social}^{7}$ ).

No, son todos de acá [los que habitan conjuntos de vivienda social], bueno los hijos van creciendo, van teniendo su familia... había mucho hacinamiento, una familia, papá, mamá, hijos y estos chicos crecían, formaban su familia y no tenían el requisito de poder tener o arrendar una vivienda y vivían en la parte posterior, el patio trasero de estas viviendas, que ya de por sí, era pequeñitas y se generan estos hacinamientos excesivos (director de obras municipales, comuna del periurbano norte del AMGS, comunicación personal, abril 2018).

Esto fue respaldado por la encuesta aplicada a residentes de vivienda social construidas a partir de 2000 en las zonas de expansión identificadas. En ella, el porcentaje de jefes de hogar o cónyuges que ya residía en la comuna antes de llegar al conjunto es de 78,6\%, y solo un $30,6 \%$ reporta haber nacido en alguna comuna del AMGS.

Vistos en conjunto, estos datos descartan la existencia de un proceso masivo de desplazamiento de hogares asignatarios de vivienda social del AMGS hacia comunas periurbanas en el período posterior al año 2000.
No obstante, sí se pudo verificar un movimiento expulsivo de vivienda social hacia estas zonas, en especial hacia Colina y Lampa, y también hacia otras más lejanas, como Melipilla, en paralelo a la producción masiva de viviendas que dio lugar a la conformación de la periferia popular compacta, es decir, hacia fines de la década de los ochenta y durante los años noventa. Las viviendas sociales producidas en las zonas de expansión en este período quedan, en la mayoría de los casos, incorporadas en los centros históricos de sus comunas y, por ende, cercanas a los centros de servicios locales (ver, por ejemplo, el caso de Lampa, Figura 2).

En términos de segregación residencial socioeconómica, los conjuntos de vivienda social desarrollados en los años noventa en las comunas periurbanas se localizan en sectores que presentan segregación en una escala local (generalmente se encuentran dos o tres conjuntos de vivienda social contiguos), pero que en una escala más amplia pueden considerarse como bien servidos y heterogéneos socioeconómicamente, al quedar insertos en los cascos históricos de sus comunas.

En los noventa como se radicaron mucha gente de las zonas como Peñalolén, Santiago Centro, qué sé yo,

7 A diferencia de la vivienda social, la vivienda económica está orientada a hogares del segundo quintil de ingresos (es decir, un poco menos vulnerables que los que acceden a vivienda social). Se financia a través de un subsidio menor al de la vivienda social, el que se complementa por parte de las familias con ahorro y crédito hipotecario. 


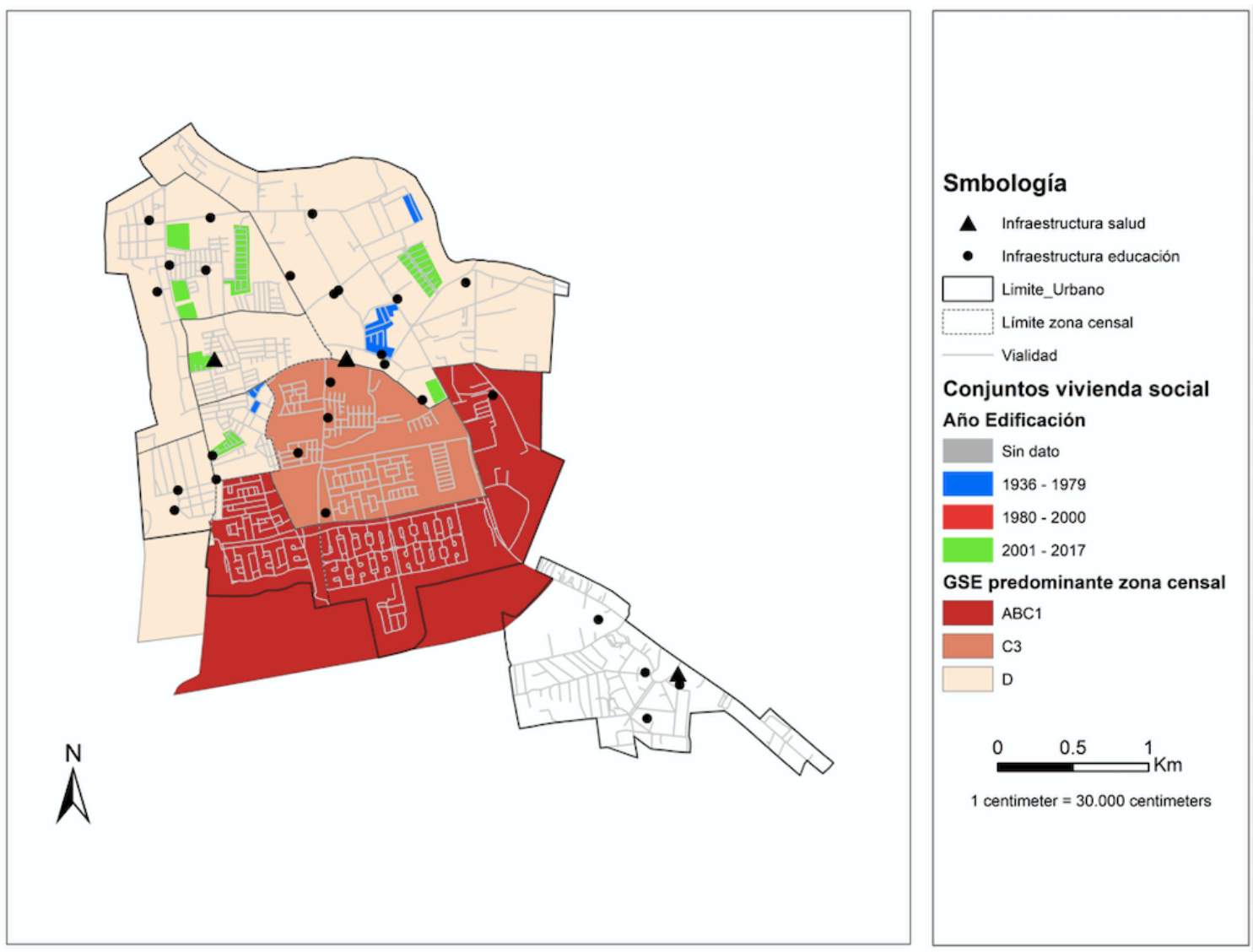

Fuente: Elaboración propia con datos del Censo 2017, Catastro de condominios sociales del MINVU y del Sistema Nacional de Información Municipal, SINIM.

tomas que habían disgregadas en los noventa, en el centro de [esta comuna] se desarrollaron poblaciones, casas PET, vivienda social, qué sé yo, que se trajo también mucha gente de sectores de Quilicura, de Recoleta... gente que estaba en toma. Y se desarrolló una población que de los años noventa hasta ahora ya hay hijos de esa gente, nietos, qué sé yo, que corresponden a una clase social baja (...). Los nuevos desarrollos han traído gente de un estrato social de clase media emergente, en realidad. Gente que es profesional, primera, segunda generación de profesionales (director de obras municipales, comuna del periurbano norte del AMGS, comunicación personal, mayo de 2018).

De este modo, hay zonas que, si bien quedan distantes o "discontinuas" respecto de la mancha urbana, son producto de procesos urbanos muy similares a los ocurridos en las comunas que, habiendo sido localidades rurales, quedaron conurbadas al AMGS durante los años noventa.

\section{El suelo en los sectores de expansión del AMGS}

En la actualidad, en cambio, la expansión sobre el periurbano está conformada principalmente por conjuntos de vivienda orientada a estratos medios y altos, bajo la figura del condominio y parcelas de $\operatorname{agrado}^{8} \mathrm{del} \mathrm{mismo}$ nivel socioeconómico (Figura 3).

Esta composición de usos del suelo permite levantar una hipótesis respecto de por qué no se han encontrado conjuntos de vivienda social en las zonas de expansión del AMGS: los precios del suelo en estas comunas se

8 Se denomina parcela de agrado a una tipología residencial que consiste en una vivienda unifamiliar edificada en un lote de 5.000 m2, ubicada una zona rural aledaña alguna localidad o pequeña ciudad. 
Figura 3

Tipologías de vivienda en zonas de expansión urbana reciente, AMGS

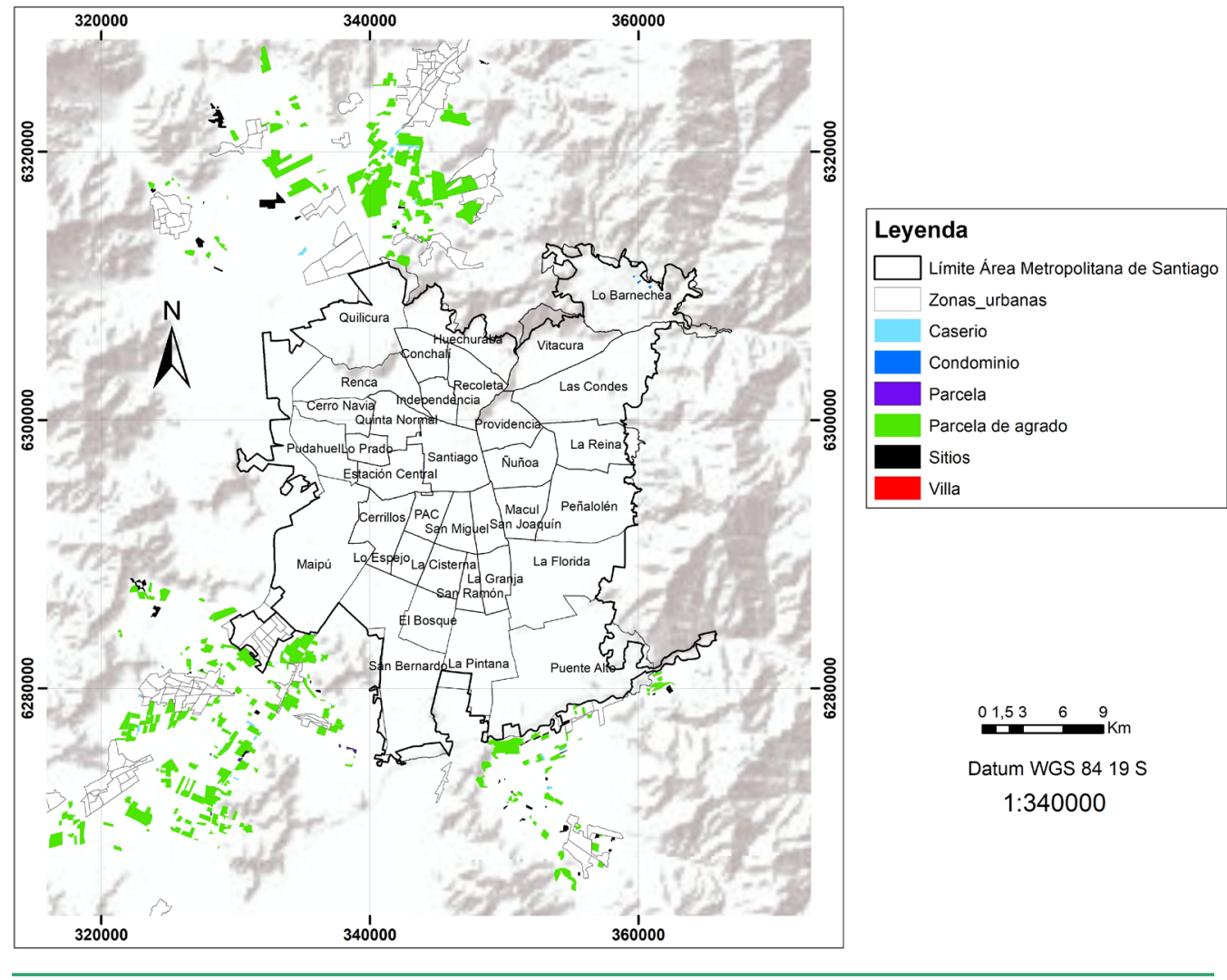

han ajustado a la expectativa de recibir desarrollos inmobiliarios correspondientes a estratos medios y altos. En este sentido, si bien el paisaje actual de estas comunas exhibe abundantes predios destinados a uso agrícola, ese suelo no está disponible al precio correspondiente a su uso actual, sino que su valor corresponde a la expectativa de un desarrollo inmobiliario de estratos medios. Incluso, en dos de las entrevistas, los directores de obras señalan de forma explícita que en la práctica ya no queda suelo disponible en su comuna para vivienda social o económica, ya que todo el suelo de uso residencial ya está en manos de desarrolladores inmobiliarios, que tienen proyectos en curso orientados a estratos medios y altos.

Ya no quedan terrenos y el sector rural está grabado en [subdivisiones mínimas de] 40.000 metros cuadrados. Hay dos AUDP 9 , la [nombra el desarrollo], y el otro que está por desarrollar (...) ni siquiera hay loteos brujos porque terrenos no quedan (director de obras municipales, comuna del periurbano poniente del AMGS, comunicación personal, mayo de 2018).

Consistente con lo anterior, en las entrevistas realizadas en los conjuntos de vivienda social en sectores periurbanos, llama la atención que varios de estos provienen en su mayoría de campamentos y comités de vivienda que esperaron largo tiempo para obtenerla. Uno de los casos de estudio, en Padre Hurtado, corresponde a una erradicación de un campamento que estuvo veinte años buscando una solución habitacional. Esto puede interpretarse como un indicador indirecto de la dificultad de los hogares de bajos ingresos para acceder al suelo, incluso en estos sectores de expansión urbana reciente. A diferencia de otros países, la espera no ha sido considerada en Chile como un mecanismo sojuzgador, denigrante ni manipulador, pese a que los beneficiarios lo destacan como un dolor muy evidente, como pudimos observar en nuestras entrevistas y en el detallado trabajo de Koppelman (2018).

9 Areas de Desarrollo Urbano Condicionado, es decir, que estan fuera de la zona urbana pero pueden ser desarrolladas por un inmobiliario si cumple con ciertas condiciones de equipamiento y provisión de servicios. 
Figura 4

Nivel socioeconómico, zonas de expansión urbana reciente, AMGS.

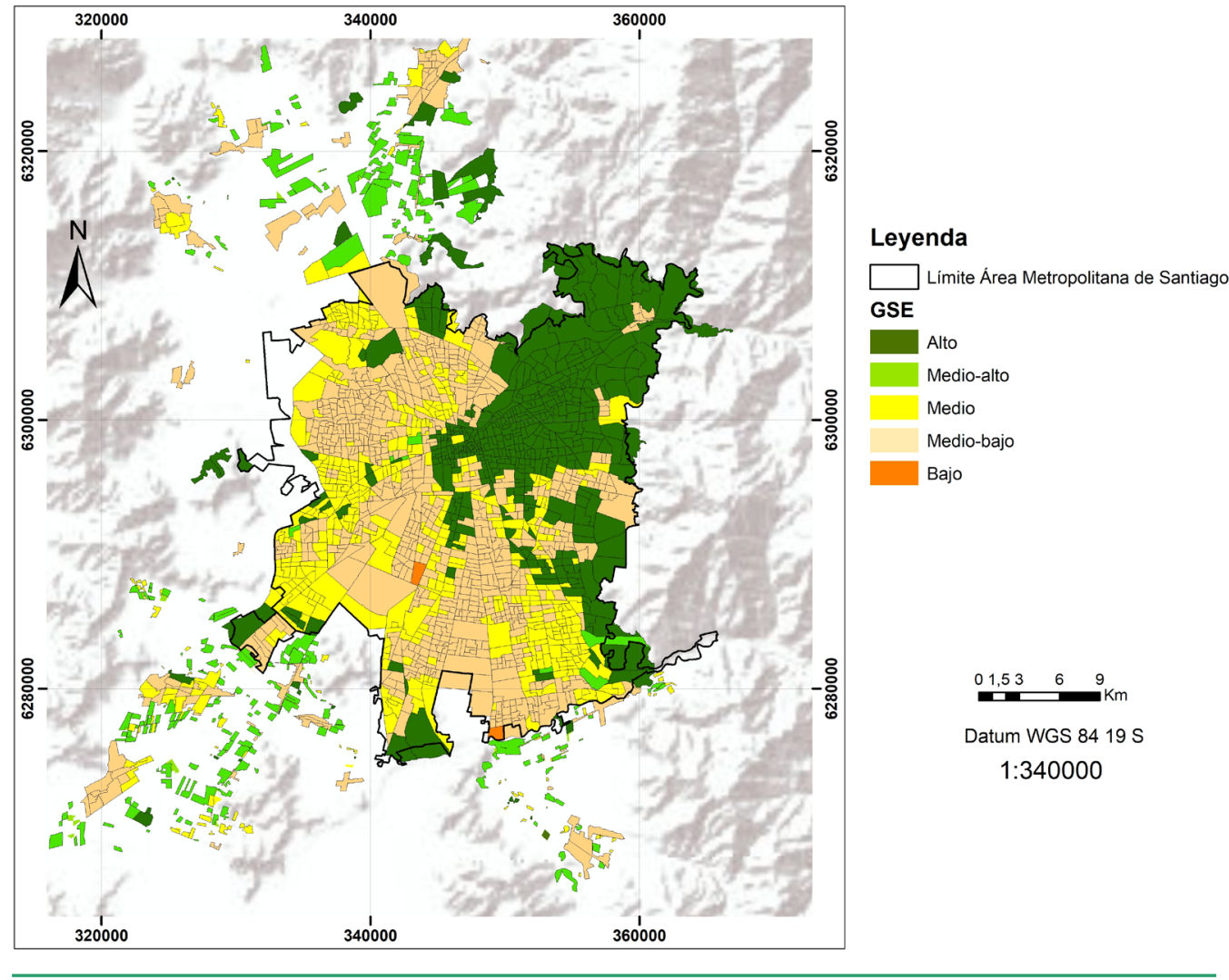

Fuente: Elaboración propia con base en datos censales 2017 y fotointerpretación.

Todo lo anterior tiene como consecuencia, como se puede observar en el Figura 1, que no se evidencie un "segundo anillo" de segregación residencial de los más pobres, por fuera de la periferia popular ya consolidada. Por el contrario, al mirar el AMGS más sus áreas de expansión, se puede ver cómo no solo la periferia popular presenta una colonización por parte de estratos medios y altos, sino que las zonas de expansión presentan predominantemente estratos medios y altos, siendo los centros históricos de las localidades conurbadas los que mantienen una presencia importante de sectores de bajos ingresos (ver Figura 4).

\section{La situación de los hogares de bajos ingresos posterior al año 2000}

Los resultados recién presentados tienen como consecuencia inmediata una pregunta: si no están en las zonas de expansión sobre el periurbano, ¿dónde están los hogares de bajos ingresos que se están formando? Si bien para responder en propiedad dicha interrogante sería necesario realizar un seguimiento de la localización y situación de tenencia de vivienda de todos los hogares de bajos ingresos conformados con posterioridad al año 2000, existen datos secundarios que nos permiten elaborar una hipótesis respecto de su situación.

De acuerdo con el catastro nacional de campamentos realizado por el MINVU (2019), las familias habitando en campamentos en la Región Metropolitana de Santiago (RMS) han aumentado de 4.645 en 2011 a 5.991 en 2018, número que, de acuerdo con Techo (2021), llega a 19.444 en 2021. Producto de los fuertes procesos de migración experimentados por el país en los últimos años, podría pensarse que este aumento de las familias en campamento está dado principalmente por familias migrantes. Si bien en las regiones del norte del país este componente es claro y mayoritario, en el resto de las regiones del país aún la situación mayoritaria en los campamentos es que el jefe de hogar sea chileno: un 70\% de los jefes de hogar en campamentos es chileno. En este sentido, si bien hay un factor relativo a la migración que debe ser estudiado en mayor profundidad, en los campamentos actúan 

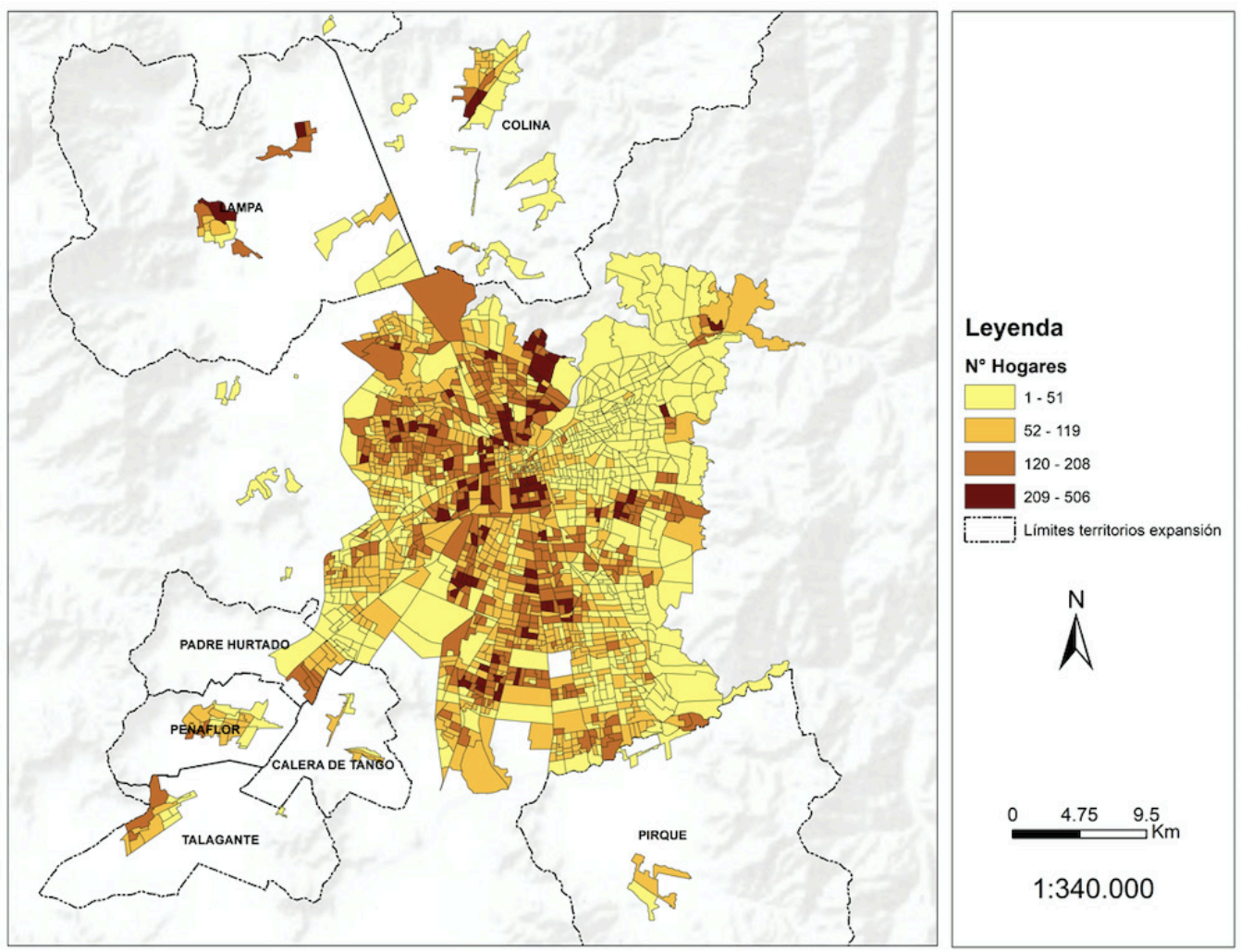

Fuente: Elaboración propia con base en Censo 2017.

fuerzas de exclusión urbana más amplias (como sugiere López-Morales, Flores y Orozco, 2018), y que afectan tanto a migrantes como a nacionales: las principales razones señaladas por los habitantes de campamentos como motivaciones para vivir ahí son el alto precio de los arriendos (31\%) y el dejar de ser allegados (24\%).

Adicionalmente, las estadísticas oficiales correspondientes a la serie histórica de la encuesta $\operatorname{CASEN}^{10}$ señalan que entre 2000 y 2017 los hogares allegados en la RMS se incrementaron de 37.319 a 175.377. El déficit habitacional cuantitativo total aumentó de 165.086 a 270.641 viviendas en el mismo período (Figura 5).

Al localizar el déficit habitacional de acuerdo con los datos censales disponibles, podemos observar que los hogares que constituyen dicho déficit se distribuyen casi por toda la ciudad, con excepción del sector nororiente (donde se concentran los hogares de altos ingresos).

Este patrón de localización, de dispersión casi por la totalidad del AMGS, se replica al distinguir entre los componentes del déficit (es decir, diferenciando entre hogares que residen en viviendas con materialidad precaria y hogares que viven allegados).

Las estadísticas de allegamiento y de déficit, así como su patrón de distribución en la ciudad de Santiago, sugieren que, más que un desplazamiento hacia comunas del periurbano, la dificultad para acceder al mercado habitacional formal ha llevado a los hogares de bajos ingresos del AMGS a buscar alternativas informales de vivienda asequible al interior de la ciudad. Dado que este movimiento se ha dado de forma dispersa, no se

10 Se ha preferido la utilización de los datos de serie histórica de la encuesta CASEN por sobre las estadísticas censales, en la medida en que el Censo 2017 carece de algunas de las variables para la medición del déficit habitacional de acuerdo con la metodología propuesta por el Centro Latinoamericano y Caribeño de Demografía, CELADE, lo que impide la comparación temporal. Adicionalmente, pensamos que la propuesta de ajuste metodológico desarrollada por el Ministerio de Vivienda implica la subestimación del déficit, entre otras cosas, por la eliminación del componente de saneamiento (en lugar de su modificación con base en las variables disponibles). 
ha visto reflejado en los patrones de segregación de la ciudad en la macro escala.

\section{Discusión y conclusiones}

Al mirar la ciudad como un todo, incorporando sus áreas de expansión, es posible ver que la tendencia a ir "alejando" a los pobres del centro en círculos concéntricos con el paso del tiempo, a través de las sucesivas políticas de vivienda social, no se ha replicado en la expansión de la ciudad hacia el periurbano desde el 2000. No existe evidencia de un desplazamiento masivo de los nuevos hogares pobres hacia áreas periurbanas, sino de su exclusión del mercado habitacional formal. La lectura global de los datos expuestos sugiere que los grupos populares se están localizando al interior de la metrópolis, sin llegar a conformar grandes zonas de concentración, resolviendo su acceso a vivienda a través de una serie de estrategias informales y condiciones deficitarias (allegamiento, hacinamiento, campamento). En principio, procesos como la segregación residencial, que estuvieron a la base de la producción de la periferia metropolitana por varias décadas, podrían ser menos adecuados para interpretar la actual producción del espacio relacionado con los grupos populares, donde la exclusión, e incluso la marginalidad, parecen ser marcos de análisis más pertinentes, ahora materializados en un espacio diferente al de la periferia.

En consecuencia, si la vivienda social construida en los ochenta y noventa representó un acceso al suelo sin mejorar las condiciones de acceso a la ciudad e inclusión social de sus beneficiarios, en la actualidad tenemos un escenario de extrema dificultad de acceso formal al suelo urbano, en que los hogares logran quedar insertos en la ciudad, pero en condiciones de habitabilidad deficientes y sin garantías de seguridad en la tenencia.

La expansión de la economía inmobiliaria y la ruptura del patrón tradicional de segregación residencial han traído como consecuencia que virtualmente todo terreno urbano tenga hoy un uso más rentable que la vivienda social, proceso que, lejos de quedar circunscrito a la ciudad compacta o a la vieja periferia popular, se ha proyectado sobre la región urbana de Santiago como un todo, incluyendo a sus áreas periurbanas. La baja presencia de conjuntos de vivienda social recientes en las zonas de expansión urbana responde a los mismos factores que han generado el bajo desarrollo de vivienda social al interior de la ciudad.

En términos del patrón de segregación residencial emergente en los sectores de expansión urbana, lo que puede observarse es que la expansión de la ciudad de Santiago sobre su periurbano está conformada mayoritariamente por hogares de estratos medios y altos, y que solo en los centros de las localidades que van quedando conurbadas es posible observar hogares de estratos bajos. Estos hogares habitan en contextos de segregación residencial en una escala local o reducida (la homogeneidad social se circunscribe a su propio conjunto de vivienda social o a dos o tres conjuntos de vivienda social contiguos); pero, al mismo tiempo, habitan en contextos que, vistos en una escala más amplia, son diversos socioeconómicamente.

A mirar la ciudad como un todo, lo que se evidencia es un patrón de segregación se caracterizaría por 1) la extensión del cono de alta renta a todo el oriente de la ciudad, quedando solo algunas zonas de concentración de grupos populares en parte del territorio poniente de la comuna de Peñalolén; 2) las áreas populares se concentran en el sector norte, sur, y poniente de la ciudad, pero compartiendo el territorio con otros grupos sociales, incluso medios-altos, disminuyendo así su segregación de gran escala; y (3) las áreas de expansión de la metrópolis, tanto urbanas como rurales, son progresivamente ocupadas por grupos medios-altos, siendo cada vez más difícil la localización en ellas de grupos populares. En suma, la segregación de los hogares más pobres ha disminuido su escala, aunque los grupos de altos ingresos siguen estando segregados al oriente de la ciudad.

El trade off entre vivienda social segregada y vivienda informal menos segregada que parece haber organizado la lógica de localización de los hogares populares desde 
hace largo tiempo, incluso desde antes de la política neoliberal de "subsidio habitacional", habría llegado a su fin. Dicho trade off ha sido desmantelado, al menos por ahora, mientras no cambie el modelo de acceso al suelo que subyace a nuestra actual política de vivienda, y los instrumentos que definen las formas de acceso a la vivienda para los hogares de menores ingresos. Resulta urgente, entonces, retomar el problema de la vivienda social como problema de interés público, como urgente es hacerse cargo de cambiar las condiciones de acceso a la vivienda para los hogares de bajos ingresos, con el fin de pueda materializarse el derecho humano a una vivienda adecuada, y se favorezca el camino hacia una ciudad inclusiva y sustentable.

\section{Referencias bibliográficas}

\section{4}

Aguilar, A. G., Ward, P., \& Smith Sr, C. (2003). Globalization, Regional Development, and Mega-city Expansion in Latin America: Analyzing Mexico City's Peri-urban Hinterland. Cities, 20(1), 3-21. https://doi.org/10.1016/S02642751(02)00092-6

Ahumada, J. (1958). En vez de la miseria. Editorial del Pacífico.

Brain, I., Prieto, J. y Sabatini, F. (2010). Vivir en campamentos: ¿camino a la vivienda formal o estrategia de localización para enfrentar la vulnerabilidad? EURE, 36(109), 111-142. http://dx.doi.org/10.4067/S0250-71612010000300005

Bordé, J. (1954). L'essor d'une capitale: Santiago-du-Chili. Les Cahiers d'Outre-Mer, 7(25), 5-24.

Cáceres, G. (2017). Política y ciudad bajo el reformismo urbano: el Santiago del sexenio progresista (1964-1970). Estudios del Hábitat, 15(1), 1-13. http://sedici.unlp. edu.ar/handle/10915/61049

Calderón, J. (2003). Los barrios marginales de Lima, 1961-2001. Ciudady Territorio. Estudios Territoriales, 35(136/137), 375-390. https://recyt.fecyt.es/index.php/CyTET/article/view/75397

Cariola, C. y Soler, F. (1969). Algunos efectos de las políticas de vivienda en el crecimiento metropolitano de Santiago
(Documento detrabajo CIDU n ${ }^{\circ}$ 6). https://scielo.conicyt.cl/ scielo.php?script=sci_nlinks\&ref $=2127397 \&$ pid $=$ S02507161200700010000400006\&lng=es

Castillo M. e Hidalgo, R. (Eds.) (2007). 1906/2006 Cien años de política de vivienda en Chile. Facultad de Arquitectura y Diseño UNAB, Facultad de Historia, Geografía y Ciencia Política PUCCH.

Centro para el Desarrollo Económico y Social de América Latina, DESAL (1964). América Latina y desarrollo social. Antártica.

Centro para el Desarrollo Económico y Social de América Latina, DESAL (1967). Marginalidad en América Latina. Un ensayo de diagnóstico. Herder.

Comisión Económica para América Latina y el Caribe, CEPAL (1963). La urbanización de América Latina: resultados de un trabajo sobre el terreno acerca de las condiciones de vida de un sectorurbano (Documento de trabajo de la décima sesión). https://repositorio.cepal.org/handle/11362/14736

De Soto, H. (1987). El otro sendero. Editorial Sudamericana.

Ducci, M. (1997). Chile: el lado obscuro de una política de vivienda exitosa. Eure, 23(69), 99-115. http://mail.eure. cl/index.php/eure/article/view/1164

Ducci, M. (2002). Área urbana de Santiago 1991-2000: expansión de la industria y la vivienda. EURE, 28(85), 187-207. http://dx.doi.org/10.4067/S0250-71612002008500010

Elorza, A. L. (2016). Segregación residencial socioeconómica y la política pública de vivienda social. El caso de la ciudad de Córdoba (Argentina). Cuaderno Urbano. Espacio, Cultura, Sociedad, 20(20), 71-94. http://dx.doi.org/10.30972/ crn. 2020943

Fuentes, L. y Pezoa, M. (2018). Nuevas geografías urbanas en Santiago de Chile 1992-2012. Entrela explosión y la implosión de lo metropolitano. Revista Geografía Norte Grande 70, 131-151. http://dx.doi.org/10.4067/S0718-34022018000200131

Galleguillos, X. (2000). La satisfacción residencial y la 
segregación urbana en un contexto de pobreza. Caso de estudio: Esperanza Andina, Peñalolén [Tesis de Magíster no publicada]. Instituto de Estudios Urbanos y Territoriales, Facultad de Arquitectura y Estudios Urbanos, Pontificia Universidad Católica de Chile, Santiago.

Giusti, J. (1973). Organización y participación popular en Chile: El mito del hombre marginal. Facultad Latinoamericana de Ciencias Sociales, FLACSO.

Gorelik, A (2008). La aldea en la ciudad. Ecos urbanos de un debate antropológico. Revista del Museo de Antropología, 2(1), 73-96. https://revistas.psi.unc.edu.ar/index.php/ antropologia/article/view/5398

Hauser, P. (Ed.) (1967). La urbanización en América Latina. Solar, Hachette.

Harvey, D. (1973). Social Justice and the City. University of Georgia Press.

Hidalgo, R. (2004). De los pequeños condominios cerrados a la ciudad vallada: las urbanizaciones cerradas y la nueva geografía social en Santiago de Chile (1990-2000). Eure, 30(91), 29-52. http://dx.doi.org/10.4067/S025071612004009100003

Hidalgo, R. (2007). ¿Se acabó el suelo en la gran ciudad? Las nuevas periferias metropolitanas de la vivienda social en Santiago de Chile. Eure, 33(98), 57-75. http://dx. doi. org/10.4067/S0250-71612007000100004

Hidalgo, R. y Borsdorf, A. (2005). La exclusión residencial y el desarrollo de la ciudad moderna en América Latina: de la polarización a la fragmentación. El caso de Santiago de Chile. Geographicalia, 48, 5-29. https://doi.org/10.26754/ ojs_geoph/geoph.2005481322

Hidalgo, R., Borsdorf, A., Zunino, H. y Álvarez, L. (2008). Tipologías de expansión metropolitana en Santiago de Chile: precariópolis estatal y privatópolis inmobiliaria. Scripta Nova 270(113). http://www.ub.edu/geocrit/xcol/434.htm
Hidalgo, R., Salazar, A., Lazcano, R., Roa, F., Alvarez, L. y Calderón, M. (2005). Transformaciones socioterritoriales asociadas a proyectos residenciales de condominios en comunas de la periferia del área metropolitana de Santiago. INVI, 20(54), 104-133. https://adnz.uchile.cl/ index.php/INVI/article/view/8719

Imilan Ojeda, W. (2016-05). Políticas y luchas por la vivienda en Chile: el camino neoliberal (Working paper series Contested Cities). http://repositorio.uchile.cl/ handle/2250/141198

Imilan, W., Olivera, P. y Beswick, J. (2016). Acceso a la vivienda en tiempos neoliberales: un análisis comparativo de los efectos e impactos de la neoliberalizacion en las ciudades de Santiago, México y Londres. Revista INVI, 31(88), 163-190. http://dx.doi.org/10.4067/S071883582016000300006

Instituto Nacional de Estadísticas de Chile, INE (2012). Censo de Población y Vivienda 2012.https://www.ine.cl/ estadisticas/sociales/censos-de-poblacion-y-vivienda

Instituto Nacional de Estadísticas de Chile, INE (2017). Censo de Población y Vivienda 2017. https://www.ine.cl/ estadisticas/sociales/censos-de-poblacion-y-vivienda

Inzulza, J. y Galleguillos, X. (2014). Latino gentrificación y polarización: transformaciones socioespaciales en barrios pericentrales y periféricos de Santiago, Chile. Revista de Geografía Norte Grande, 38, 135-159. http:// dx.doi.org/10.4067/S0718-34022014000200008

Janoschka, M. (2002) El nuevo modelo de la ciudad latinoamericana: fragmentación y polarización. Eure, 28(85), 11-20. http://dx.doi.org/10.4067/S0250$\underline{71612002008500002}$

Janoschka, M. \& Borsdorf, A. (2004). Condominios fechados and barrios cerrados: The rise of private residential neighborhoods in Latin América. En G. Glasze, C. Webster, \& C. Frantz (Eds.), Private Neighbourhoods. Global and Local Perspectives (pp.89-104). Routledge. 
Kaztman, R. y Wormald, G. (2002). Trabajo y ciudadanía. Los cambiantes rostros de la integración y la exclusión social en cuatro áreas metropolitanas de América Latina. Cebra.

Koppelman, C. (2018). "For now, we are in waiting”: Negotiating time in Chile's social housing system. City and Community, 17(2), 504-525. https://doi.org/10.1111/cico.12301

Lewis, O. (1972). La cultura de la pobreza. Anagrama.

Link, F. (2008) De la policentralidad a la fragmentación en Santiago de Chile. Centro-h, 2, 13-24. https://www. redalyc.org/articulo.oa?id=115112535002

López Morales, E. (2013). Gentrificación en Chile. Aportes conceptuales y evidencias para una discusión necesaria. Revista de Geografía Norte Grande, 53, 31-52. http:// dx.doi.org/10.4067/S0718-34022013000300003

López Morales, E., Flores, P. y Orozco, H. (2018) Inmigrantes en campamentos en Chile: ¿Mecanismo de integración o efecto de exclusión? Revista INVI 33(94), 159-185. http://dx.doi.org/10.4067/S0718-83582018000300161

Massey, D. \& Denton, N. (1988). The Dimensions of Residential Segregation. Social Forces, 67(2), 281-315. https://doi. org/10.1093/sf/67.2.281

Méndez, M. \& Gallo, M. (2018). Upper Middle-Class Reproduction. Wealth, Schooling and Residential Choice in Chile. Palgrave Mcmillan.

Ministerio de Desarrollo Social y Familia de Chile, Observatorio Social (2017). Encuesta de Caracterización Socioeconómica Nacional, CASEN 2017. http://observatorio. ministeriodesarrollosocial.gob.cl/encuesta-casen-2017

Ministerio de Vivienda y Urbanismo de Chile, Minvu (2004). El déficit habitacional en Chile. http://observatoriodoc. colabora.minvu.cl/Documentos\%20compartidos/ ESTUDIOS\%200BSERVATORIO/Deficit $\% 20$ Habitacional2002.pdf
Ministerio de Vivienda y Urbanismo de Chile, Minvu (2019). Catastro nacional de campamentos. https://www.minvu. cl/catastro-de-campamentos/

Ministerio de Vivienda y Urbanismo de Chile, Minvu (2021) Catastro de condominios sociales. https://ide.minvu. cl/datasets/b632432ce6b649c6afc09c24125b6930

Molina, I. (1985). El Programa de Erradicación de Campamentos en la Región Metropolitana de Santiago (1979-1984): implicancias socioeconómicas y espaciales [Tesis de pregrado no publicada]. Instituto de Geografía, Pontificia Universidad Católica de Chile.

Morales, E. y Rojas, S. (1986). Relocalización socio-espacial de la pobreza. Política estatal y presión popular, 19791985 (Documento de trabajo ${ }^{\circ}{ }^{2} 280$ ). Programa FLACSO - Santiago de Chile.

Ortiz, J. y Morales, S. (2002). Impacto socioespacial de las migraciones intraurbanas en entidades de centro y de nuevas periferias del Gran Santiago. EURE, 28(85), 171-185. http://dx.doi.org/10.4067/S0250-71612002008500009

Parraguez, W. (1947). La vivienda problema nacional. Arquitectura y Construcción, 8, 29-33.

Perlman, J. (1976). The Myth of Marginality, Urban Poverty and Politics in Rio de Janeiro. University of California Press.

Portes, A. (1989). La urbanización de América Latina en los años de crisis. En M. Lombardi y D. Veiga (Ed.), Las ciudades en conflicto (pp. 81-134). Ediciones de la Banda Oriental.

Pírez, P. (1994). La formación de la ciudad metropolitana de Buenos Aires: de la riqueza al deterioro. EURE, 20(61), 27-39. https://repositorio.uc.cl/xmlui/bitstream/ handle/11534/3633/000158415.pdf

Queiroz, L. (2003). Segregación, desigualdad y vivienda: la metrópolis de Río de Janeiro en los años 80 y 90 . Ciudad y Territorio. Estudios Territoriales, 35(136/137), 295-314. 
Rasse, A. (2015). Juntos, pero no revueltos. Procesos de integración social en fronteras residenciales entre hogares de distinto nivel socioeconómico. Eure, 41(122), 125-143. http://dx.doi.org/10.4067/S0250-71612015000100006

Rasse, A. (2019). Spatial Segregation. En A. Orum (Ed.), The Wiley Blackwell Encyclopedia of Urban and Regional Studies (pp.1-9). Wiley-Blackwell.

Roberts, B. (2007). La estructuración de la pobreza. En G. Saraví (Ed.) De la pobreza a la exclusión. Continuidadesy rupturas de la cuestión social en América Latina (pp.201231). CIESAS, Prometeo.

Robles, M. (2009). Nuevas tendencias de localización de la clase alta, media alta y media en el Gran Santiago (1992-2002) [Tesis de Magíster no publicada]. Instituto de Estudios Urbanos, Pontificia Universidad Católica de Chile.

Rodríguez, A. y Sugranyes, A. (2004). El problema de vivienda de los "con techo". EURE, 30(91), 53-65. http://dx.doi. org/10.4067/S0250-71612004009100004

Sabatini, F. (1977). Teorías del desarrollo y teorías de la marginalidad en América Latina [Tesis de pregrado no publicada]. Instituto de Sociología, Pontificia Universidad Católica de Chile.

Sabatini, F. (2000) Reforma de los mercados de suelo en Santiago de Chile. Efectos sobre los precios de la tierra y la segregación residencial. Eure, 26(77), 49-80. http://mail.eure.cl/index.php/eure/article/view/1194

Sabatini, F. y Cáceres, G. (2004). Los barrios cerrados y la ruptura del patrón tradicional de segregación en las ciudades latinoamericanas: el caso de Santiago de Chile. En G. Cáceres y F. Sabatini (Eds.), Los barrios cerrados en Santiago de Chile. Entre la exclusión y la integración social (pp. 9-44). Lincoln Institute of Land Policy.

Sabatini, F., Cáceres, G. y Cerda, J. (2001) Segregación residencial en las principales ciudades chilenas: tendencias de las tres últimas décadasy posibles cursos de acción. EURE, 27(82), 2142. http://dx.doi.org/10.4067/S0250-71612001008200002
Sabatini, F., Campos, D., Cáceres, G. y Blonda, L. (2007). Nuevas formas de pobreza y movilización popular en Santiago de Chile. En G. Saraví (Ed.), De la pobreza a la exclusión. Continuidades y rupturas de la cuestión social en América Latina (pp.97-136). CIESAS, Prometeo.

Sabatini, F., Rasse, A., Cáceres, G., Robles, M. y Trebilcock, M. (2017). Promotores inmobiliarios, gentrificación y segregación residencial en Santiago de Chile. Revista Mexicana de Sociología, 79(2), 229-260.

Sabatini, F. y Salcedo, R. (2007). Gated Communities and the Poor in Santiago, Chile: Functional and Symbolic Integration in a Context of Aggressive Capitalist Colonization of Lower-Class Areas. Housing Policy Debate, 18(3), 577-606. https://doi.org/10.1080/105 11482.2007 .9521612

Sabatini, F., Wormald, G. y Rasse, A. (Eds.) (2013). Segregación de la vivienda social. Ocho conjuntos en Santiago, Concepción y Talca. Colección Estudios Urbanos UC.

Salazar, A. y Osses, P. (2008). La ruralidad en la región metropolitana de Santiago de Chile (2002): determinación y relación con los grupos socio-profesionales. Scripta Nova, 12(270). https://revistes.ub.edu/index.php/ ScriptaNova/article/view/1535

Salcedo, R. y Rasse, A. (2017). Autosegregación de las clases altas en Santiago de Chile: Fragmentación cultural y espacial. En T. Errázuriz y R. Greene (Eds.), Salcedo (pp.108-126). Editorial Bifurcaciones.

Saraví, G. (2007). Nuevas realidades y nuevos enfoques: exclusión social en América Latina. En G. Saraví (Ed.), De la pobreza a la exclusión. Continuidades y rupturas de la cuestión social en América Latina (pp.19-52). CIESAS, Prometeo.

Saraví, G. (2020). Acumulación de desventajas en América Latina: aportes y desafíos para el estudio de la desigualdad. RELAP Revista Latinoamericana de Población, 14(27), 228-256. https://doi.org/10.31406/relap2020.v14. i12.n27.7 
Savage, M. (2010). The Politics of Elective Belonging. Housing, Theory and Society, 27(2), 115-161. https:// doi.org/10.1080/14036090903434975

Slater, T. (2009). Missing Marcuse: On Gentrification and Displacement. City - Analysis of Urban Trends Culture Theory Policy and Action, 13(2), 292-312. https://doi. org/10.1080/13604810902982250

Smith, N. (1987). Gentrification and The Rent Gap. Annals of the Association of American Geographers, 77(3), 462-465. https://doi.org/10.1111/j.1467-8306.1987.tb00171.x

Tapia, R. (2011). Vivienda social en Santiago de Chile. Análisis de su comportamiento locacional, período 1980-2002. Revista INVI, 3(26), 105-131. http://dx.doi.org/10.4067/ S0718-83582011000300004
Tapia, R. (2014). Evolución del patrón espacial de emplazamiento de viviendas sociales en Santiago, Chile. 1980-2010. Revista Geográfica Venezolana, 55(2), 255-274. https://www.redalyc.org/articulo.oa?id=347733745008

Techo (2021). Catastro Nacional de campamentos 2020-2021. https://ceschile.org/wp-content/uploads/2020/11/ Informe\%20Ejecutivo_Catastro\%20Campamentos\%20 2020-2021.pdf

Wacquant, L., Slater, T., \& Pereira, V. (2014). Territorial Stigmatization in Action. Environment and Planning A, 46(6), 1270-1280. https://doi.org/10.1068/a4606ge 